\title{
Remedies for criminal injustice in China
}

\begin{abstract}
Background: China has responded to typical criminal injustices in capital cases in order to remedy such injustices and better prevent future miscarriages of justice. This paper starts from studies of injustice cases that reveal how remedies are often tainted, in order to examine the actual effect of implementing current justice systems. Case SHE Xianglin and Case ZHAO Zuohai are milestones of Chinese reforms on its criminal justice. The judicial rectification of the both wrongly convicted does not only suggest potential prospects for further reforms in contemporary China, but also reveal that it still has a long way to go before achieving justice.
\end{abstract}

Keywords: remedy injustices, reform proposals, preventing future injustices, China
Volume 6 Issue 5 - 2018

\author{
Jiang $\mathrm{Na}$, Wang Yue \\ College for Criminal Law Science, Beijing Normal University, \\ China
}

Correspondence: Jiang $\mathrm{Na}$, College for Criminal Law Science, Beijing Normal University, China, Tel 8610-588040II, Email na.jiamg@bnu.edu.cn

Received:September 27, 2018 | Published: November 13, 2018

\section{Introduction}

The revisions of Criminal Procedure Law of the PRC (2012 CPL) are designed to advocate 'respecting and protecting human rights' as a legal principle of criminal procedures in China's practice. In promoting the new revisions, Case SHE Xianglin and Case ZHAO Zuohai have been milestones of Chinese reforms on its criminal justice. ${ }^{1}$ Ironically, external bodies issued China's human rights reports, ${ }^{2}$ including its extensive use of extralegal detention, widespread practice of torture and other flawed justice in practice. The actual implementation of new reforms has been watched by various human rights groups ${ }^{3}$ in order to fill in the gap between legal requirements and poor implementation. It is necessary for China to learn lessons from the past experience and explore whether it is possible or not to establish a new mechanism for adequate remedies of repeated criminal injustices and if so, how to make it on the ground.

This paper starts from studies of injustice cases that reveal how remedies are often tainted, so as to examine the actual effect of implementing current justice systems. The wrongful convictions of SHE Xianglin and of ZHAO Zuohai have contributed to China's justice reforms, whose judicial rectifications brought China a lot of responsive reforms. Further, this research will conclude with creation of a new remedy model, which would be suitable for better remedying miscarriages of justice in contemporary China towards the rule of law.

\section{Case studies}

\section{The SHE xianglin case}

The conviction of SHE Xianglin is related to the crime of murdering his wife. SHE Xianglin's wife disappeared in January 1994 from Yanmenkou Township of Jingshan County in Central China's Hubei Province. Three months later, a female body was found in a pond in the township and relatives of the missing woman identified it as Zhang.

\section{Wrongful conviction in the first instance}

Local police charged the husband SHE Xianglin with murdering his wife. He was arrested in April 1994 and had been in custody ever since. After 10 days of interrogations involving beatings and sleep deprivation, he confessed. He was sentenced to death, despite numerous discrepancies in his story, the lack of a murder weapon or any DNA testing to confirm that the body was that of his wife.
On 28 August, 1994, the former Jingzhou District Prosecuratorate prosecuted SHE Xianglin for the suspected crime of his intentional homicide. On 13 October, 1994, the former Jingzhou District Intermediate People's Court made the first-instance judgement, identifying that SHE Xianglin killed his wife and committed the crime of intentional homicide, consequently sentencing him to death with a deprivation of political rights for his life.

\section{Wrongful conviction in the second instance}

On 10 January, 1995, after the case was appealed to the Hubei Provincial HPC, the HPC made a criminal ruling of No.20 (1995) in the procedure of second instance, to revoke the first-instance judgment and remand the case for a retrial.

\section{Wrongful conviction in the retrial procedure}

On 7 February, 1996, Jingshan County People's Procuratorate following a supplementary investigation, transferred the case to the former Jingzhou District Procuratorate for prosecution, and later returned it for investigation again. On 23 November, 1997, due to the change of administrative divisions, the Jingshan County Procuratorate submitted the case to the Jingmen Municipal People's Procuratorate for prosecution. On 15 December, 1997, Jingmen Municipal People's Procuratorate, after examination, considered the offences of SHE Xianglin not serious enough to be imposed criminal punishment more severe than life imprisonment and transferred the case to the Jingshan County People's Procuratorate for prosecution.

On 15 June, 1998, Jingshan County Court sentenced SHE Xianglin to 15 years' imprisonment with a deprivation of political rights for five years for intentional murder. On 22 September, 1998, the Jingmen Municipal IPC dismissed the appeal from SHE Xianglin and upheld the original judgment, which was the final ruling in the procedure for second instance in retrial. Then, SHE Xianglin served a sentence in Shayang prison.

On 28 March, 2005, Zhang Zaiyu who was considered to be dead in the past 11 years turned up alive and returned home, which proved his factual innocence. The fact led to local courts' judicial rectification of his wrongful conviction in this year. On 13 April, 2005, SHE Xianglin was declared innocent and released during a retrial by Jingshan court in Hubei Province. Also, those extorting him to confess by means of torture or degrading treatment were investigated and examined for prosecution. ${ }^{4}$ In August 2005, SHE Xianglin's lawyer helped him 
obtain state compensation for criminal injustices against him by local courts and financial aid in order to support his family members' life from the county government. ${ }^{5}$ The wrongly convicted SHE Xianglin still seeks more, given that distress over appealing his case led to his mother's early death and that the poverty caused by his trial and imprisonment forced his daughter to leave school. ${ }^{6}$

\section{Doubts in the misjudged case}

Case SHE Xianglin remained four major doubts on why not do a parenthood test, how to determine the time of committing crimes, whether anyone had seen his wife and why different testimony of the course that an offence was committed.

\section{Why to identify the dead body by her height only?}

Police investigators should not ascertain the deceased as Zhang Zaiyu, just from body features as the police described. As Zhang's brother remembered, a legal medical expert said that the dead body lasted about 80 days, judged from the deceased's decomposed degree, which is also consistent with her as far as time concerned.

Then, Zhang's family proposed to further confirm the corpse, but the local police asked Zhang's family to pay 20,000 yuan for a parenthood test because of no outlay for handling cases. According to presentation by SHE's brother, then they did not see the dead body, and police answered them that 'it is not you to have the final say, the government is certainly not wrong', when being asked whereby to identify it at the police station.

\section{Did SHE Xianglin really have time to commit crimes?}

As described in the appeal letter from SHE, the police found out that the stone used to kill the deceased and snakeskin-like bad for sinking of its body came from the bus SHE took, for which there is no sufficient evidence to prove, but only rely on She's statements and scene evidence.

\section{No attention paid to the proof that anyone saw his wife}

In Case SHE Xianglin, two documents to prove villagers' seeing Zhang Zaiyu are in great concern. After SHE Xianglin was sentenced to death on 27 December, 1994, his brother, SHE Suolin who vioced grievances for SHE, inquired about Zhang Zaiyu's (also Zhang Aiqing's) appearance at one time, and several villagers who helped her wrote a proof on the Course of Zhang Aiqing's Arrival at Our Village.

Henceforth, SHE Suolin brought the prepared materials and a petition to policemen who handled the case and the departments concerned, but did not receive any attention. As SHE Suolin recalled, the police investigators replied to him that 'we have seen many of things like yours and shall consider again if you are able to find ZHANG Zaiyu back'. As ZHANG Zaiyun's younger brother said, 'if they go to investigate, such things would probably not happen'.

\section{Why did one person provide four different confessions for the same crime?}

SHE Xanglin has successively explained four different courses of committing an offence and five kinds of motives to kill his wife, with many doubts as we feel then. Such is the opinion of a spokesman from the Hubei Provincial HPC, on Case SHE Xianglin. The fact is that SHE never murders a wife, but why he had to admit murder? In prison, SHE who had scars all over, with broken fingers and bare blue veins, mentioned in his appeals time after time that SHE had never slept for 10 days and nights after being arrested. "I just want to sleep for a while, however they prompted, whatever I followed to say, as SHE Xianglin wrote a complaint letter in 1998.

\section{The ZHAO zuohai case}

The conviction of Mr. ZHAO Zuohai, a 57 year farmer, is also related to the crime of murder. After over one decade's wrongful imprisonment, ${ }^{7}$ the fact that the assumed victim of his murder case returned alive revealed obvious errors in his convictions and sentences. Three judges involved in the wrongful conviction were reportedly subsequently suspended. ${ }^{8}$ ZHAO Zuohai finally obtained money including extra financial aid, ${ }^{9}$ following his application for state compensation. ${ }^{10}$ This compensation was obviously insufficient, given that his wife divorced him during his imprisonment and that his children were adopted by others without parents' care.

\section{Policy recommendations based on SHE's or ZHAO's wrongful conviction}

\section{Comments on misjudged cases}

The crux of both cases on judicial proceedings, tends to include such lessons as the presumption of guilt rather than innocence, use of illegally extorted evidence, abuse of power to remand a case for retrial, decision-making before a trial and so on. Among them, abuse of power to remand a case for retrial appears to be a unique complexity of the cases and turning point of its misjudged course, correction of which triggers the SPC's restoration of the power to a final review of death sentences.

Some courts eager to meet quotas let errors in criminal cases slide by, hoping that higher jurisdictions would take notice and reverse the ruling, but not all suspects are lucky enough to escape flawed verdicts. Meanwhile, other features are of special importance to prevention of miscarriages because a combination of them tends to demonstrate the most knotty questions and primary disadvantages in all of famous wrongful convictions. For instance, suspects are often treated as guilty from the start in China, whereas both cases help us understand the importance of presumption of innocence in order to protect our human rights. Concerning the other turning point of both cases, the coordination meeting of high specification should become an opportunity of clearing SHE's grievances, but resulted in a compromise approach. According to introduction by one judge who knows the inside story, the case was finally reported to the Political and Legal Committee of Jinmen City for co-ordination, because insufficient evidence cannot make for the case's going through the procedure or being withdrawn.

In the afternoon on 8 October, 1997, for example, the coordination meeting decided to impose SHE Xianglin a downgrade punishment for his intentional homicide in Case SHE, which will be prosecuted by the Jingshan County Procuratorate to the Jingshan County Court that sentenced him a fixed-term imprisonment. After about six months, the case was prosecuted by the Jingshan County People's Procuratorate to accuse SHE Xianglin of intentional homicide in the Jingshan County Court on 31 March, 1998. In procedural materials, SHE wrote his refusal to signature due to finding that two judges did not follow what he said to record, on 9 June, 1998 when the presiding judge ZHU Yuanying and Acting Judge DUAN Hongbing interrogated him. 
On 15 June, 1998, SHE Xianglin was sentenced to 15 years' imprisonment, with an additional deprivation of his political rights for five years, but SHE refused to accept it and appealed to the Jingmen City IPC. SHE Xianglin stressed that there was no time for him to commit an offence on appeal, and mentioned to repeatedly explain his looking for wife then and taking two passing buses meantime, when Jingshan County police arraigned him, which has been approved by drivers who gave a life to him through the police's investigation. However, the following judgment did not mention the testimony of two drivers who ever saw SHE at the night. On 22 September, 1998, Jingmen City Court dismissed his appeal in the procedure for second instance and maintained the original judgment as a result of first instance. Hence, lessons should be learned from the both cases. It is necessary for China to eliminate all of justice interference from outside bodies, and to promote justice authorities to independently exercise their judicial power by law. The outcome of both cases resulted from coordination that the Politics and Legal Committee at both the city and county levels organized case-handling units and investigators related to present clear suggestions, after which the two levels of courts concerned made judgments. This is similar to the approach of decision-making first and then trying cases, contrary to the relevant provisions of criminal procedure law, which is the important reason for miscarriages of justice, occurred in China. Trial bodies should handle cases strictly in accordance with the law, and the court must conduct an independent trial by law, even if the relevant departments organize coordination.

\section{Policy recommendations}

Fundamental flaws have promoted correction of and remedy for such convictions. Such tragic stories play out in the headlines. China is actively in the midst of responsive transformation of its judicial sector or official adoption of new methods. Following SHE Xianglin's and Zhao Zuohai's exoneration, the critical media at home and abroad has pushed China to take on a series of judicial reform. In summary, from the lessons of their wrongful convictions, reform proposals have been recommended, mainly including:

i) Final examination of all of capital cases involving the immediate execution of the death penalty;

ii) Revision on the 1994 State Compensation Law (SCL);

iii) Restricting the number of crimes publishable by death in China's Criminal Code;

iv) Restriction on the times of remanding cases back cases; and

v) Enshrinement of a presumption of innocence. Among them, the former two proposals have been implemented, i.e., pursuant to the 2010 SCL, as the first wave of reforms, followed with the third and fourth proposals included in the $2012 \mathrm{CPL}$ as the second.

Also, based on the lessons from ZHAO's wrongful conviction, reform proposals have contained various measures on judicial supervision and restraint mechanisms to curb such convictions, particularly on coerced confession.

Unfortunately, the new law still remains shortfalls to be mended and its implementation may lead to ineffective prevention of criminal injustices as usual. An impartial and independent watchdog was recommended to investigate again the illegal conduct of personnel responsible for wrongful convictions after they have been found, but it has not yet been practised. ${ }^{10}$

\section{Evaluation on remedies for injustice}

The above case studies provide an example of major methods of overturning wrongful convictions provided by Chinese criminal justice systems. In both cases, local courts finally granted new appeals to reopen the cases, due to the appearance of fresh evidence that confirmed criminal facts in their original judgments to be wrong, according to Article 204 of the 1996 Criminal Procedure Law of the PRC. Academic reports recommend how to remedy wrongful convictions after their occurrences. These proposals contribute to promoting quick legislative action to deal with problems as they emerge as follows.

\section{Passive judges}

As Case SHE Xianglin and Case ZHAO Zuohai have indicated, decision-makers at trial had much discretion so that courts deferred to them when deciding whether to accept a confession or not, even though they were both potentially under the pressure of the Committee's instructions. It was only after the 2010 Reform, which responded to the judicial exoneration of Mr. ZHAO, that judges were able to actively play their due role by law. Apart from restricting the admissibility of evidence that is likely detrimental to criminal justice, judges made creative decisions on such cases and exonerated the wrongly convicted by law at retrial. Finally, errors in the capital case were corrected where the innocent accused faced death sentences merely based on uncertain evidence, when discussing case lessons and reform proposals in 2010 .

\section{Insufficient compensation}

Although China has adopted a policy of compensation for victims suffering from criminal injustices, its mechanism and the amounts offered to the wrongfully convicted are clearly inadequate. Like many American states and the UK, China enacted its SCL, which was revised in 2010 to implement international standards for state compensation for the wrongfully convicted as showed in core international human rights treaties. Following a decision to compensate, the organs for compensatory obligation are supposed to pay and then apply for remuneration from the competent authority of state finance.

Unfortunately, the $2010 \mathrm{SCL}$ is quite restrictive and excludes the innocent's accused family members from its application, with very low amount of compensation. Its compact procedure also involves secret hearing, lacks effective participation and goes against justice.

Even so, some awards of compensation did not follow the restrictions and out-of-court agreements could be resolved against the interest or intention of the compensated. For example, Mr. SHE was granted state compensation for injustices committed against him by law, as well as financial aid from the county government, on the basis of settlement agreements. ${ }^{5}$ Similarly, after signing the contract with the IPC at 2 am when he was very confused, Mr. ZHAO obtained compensation, including the extra payment as financial aid and not mental distress. ${ }^{5}$ As in most payments for wrongs, those paid to the wrongfully convicted are not generous but very less in China, where the SCL likely reduces the disparity in diverse awards, but lead to fewer payments even in egregious wrong cases.

\section{More remedies but less injustice}

The two waves of justice reforms in China mainly includes implementing its $2010 \mathrm{SCL}$ in an attempt to prevent misjudged 
capital cases, and its 2012 CPL and 2010 Evidence Rules, so as to mend the flaws remained in the first wave of reforms. Most notably, a series of accused's rights, such as those seeking exclusion of illegally obtained evidence, mandatory recording of interrogations, access to legal counsel and to present expert witnesses with their attendance in court, has been introduced in the $2012 \mathrm{CPL}$. Concerning preventing torture of suspects, the $2012 \mathrm{CPL}$ has made clear that confessions extorted through illegal means, such as torture, and witness testimony and depositions of victims obtained illegally, such as by violence or threats, should be excluded during the trials. To institutionally prevent extortion of confession by torture, it has regulated that suspects be sent to a detention facility for custody after being detained or arrested and be interrogated there, apart from the audio or video-taped process of interrogation. ${ }^{11}$ Revisions on ruling out illegal evidence and strictly regulating the procedure of collecting evidence are designed to effectively curb torture. As to reviewing death sentence, it also specifies the procedures for the SPC to review death penalty cases for its sufficient care and legal oversight strengthened. ${ }^{12}$

A revision allowing the criminal suspect to engage a lawyer as his defence counsel when the police first interrogate him has been widely welcomed by lawyers, which expands the rights of lawyers at the investigation stage. Moreover, the revision incorporates regulations from the Law on Lawyers to ease restrictions on lawyers' meeting with their clients in custody. In terms of compulsive measures, additionally, the criteria for detention and the procedure for procuratorates to approve arrest and detention have been improved. Lawmakers have strictly limited the situations where family members are not notified after a person has been subjected to compulsive measures. In the chapter on investigation, provisions on interrogating criminal suspects and defenders have been improved and supervision over investigation activities been tightened up. In trials, the range of cases, whose second trial must be an open session, have been clarified and detailed provisions for the procedure of reviewing death penalty cases been laid out, as well as the added provision on community correction on enforcement.

Meanwhile, there raises a question of whether or not more remedies would definitely contribute to less injustice in China. Regrettably, China has a long way to go before achieving better justice in capital cases. Particularly, it still lacks legislation to prevent flawed checks and balances and poor defence counsel from use in criminal processes. ${ }^{13}$

China has established the system of trial for which courts are responsible for. Chinese courts independently exercise judicial power according to law, and shall not be subject to interference by any administrative organs, public organizations or individuals. That follows that Chinese people's courts may not be independent from people's procuratorates, or that people's courts at lower levels depend on instructions from those at higher levels. Meanwhile, most of Chinese judges are appointed by leaders and the presidents or chief judges of Chinese courts are selected by people's congress. Even in law, there is no independence of judges, and courts' independence is limited, differing from judicial independence in the west.

Accordingly one could assume that the legislative preconceptions require courts to pay equal attention to both: a most comprehensive fact-finding, leading to the punishment of crime, and the safeguarding of individual rights of those affected by criminal investigation, especially the defendant. By law, courts must therefore strictly examine evidence and ensure that the fact-finding process does not violate the rights of any relevant party. Also, based on legal provisions, courts should exclude illegally obtained evidence from use in conviction to ensure justice based on facts and evidence, rather than cooperate with other justice agencies or follow leaders' instructions to wrongly convict the accused. In fact, courts often use the aim of crime control ${ }^{14}$ to justify any investigative method, including torture against justice.

\section{Conclusion}

In conclusion, criminal justice reform tailored to watertight safeguards against wrongful conviction is urgently needed in China's practice. Its independent review body is most needed in better protecting the accuser's due process from criminal injustices in near future. Specifically, it is necessary for China to establish an independent review commission undertaking error correction, compensation and systemic reform like the Criminal Case Review Committee in England. Although the defence must be strengthened in China through reforms that make the system more adversarial, the present system is so unreliable that the independent review commission must be able to use inquisitorial powers to determine the reliability of convictions while more thorough reforms of its procedures against justice remain unimplemented. It is designed to counteract local Political-Legal Committees' interference into dealing with criminal cases. Hence, further reforms are needed for setting a safety net to prevent the innocent from wrongfully convicted, particularly in capital cases.

During the course of China's current shift towards adversarial processes, specifically, the proposed commission would also accept moving forward the adversarial system. But continued weaknesses in this system require inquisitorial reforms that are certainly not foreign to it, so as to combine both strengths for best prevention of wrongful convictions. Competent defence representation is required by the commission to properly review and correct them. Also, the commission should add inquisitorial features to adversarial representations and actively challenge suspect forms of evidence to determine the reliability of convictions for remedies of criminal injustices. The creative hybrid, combining both inquisitorial review and adversarial representation, would intend to engage in impartial compensation for wrongful convictions with adversarial and inquisitorial challenges to best prevent and remedy such convictions.

\section{Acknowledgements}

Many thanks to editors and reviewers who kindly offer expert advices to help improve the quality of my research.

\section{Conflict of interest}

Author declare that there is no conflict of interest.

\section{References}

1. LANG Sheng. Explanations of Criminal Procedure Law in the People's Republic of China. Beijing: China; 2012.

2. Stanley Lubman. China's Criminal Procedure Law: Good, Bad and Ugly. CHINAREALTIMEREPORT. 2012.

3. Nolan, James L. Legal Accents, Legal Borrowing. The International Problem-Solving Court Movement. 2009. 
4. Liu Zhihua. All Personnel Responsible for Handling the Misjudged Case of SHE Xianglin Killing Wife in Those Years Being in Suspended Investigation. XINHUA; 2005.

5. Yan Lin, Mu Yu. SHE Xianglin Receiving RMB 460,000 in Reconciliation of His Compensation Case. China Court; 2005.

6. Liu Li. Wrongly jailed man freed after 11 years. China Daily; 2005.

7. Xinhua. Senior Judge Suspended after a Wrongful Conviction. China Daily; 2010.

8. Hexun. Three Judges Were Interdicted for Designating a Trainee Then to Defend for ZHAO Zuohai. 2010.

9. China. Zhao Zuohai Gains RMB 120,000 Extra. 2010.
10. Lin Pinxin. Causes and Countermeasures of Criminal Wrongful Convictions. 2009:155-156.

11. Time Victoria M. Evidence Gathering: The Exclusionary Rule in China. 1 International Law Research. 2012:144-148.

12. China's New Criminal Procedure Law: Death Penalty Procedures. Duihuahrjournal. 2012

13. LIANG Bin, HE Ni Phil, LU Hong. The Deep Divide in China's Criminal Justice System: Contrasting Perceptions of Lawyers and the Iron Triangle. Crime, Law and Social Change. 2014;62(58):585-601.

14. Lewis Margaret K. Controlling Abuse to Maintain Control: The Exclusionary Rule in China. New York University Journal of International Law and Politics. 2011;43:629-697. 